\title{
Tumor fibroso solitario pleural gigante. Manejo multidisciplinario
}

\section{Giant pleural solitary fibrous tumor. Multidisciplinary management}

Jorge Lavanderos F. ${ }^{1,2}$, José Manuel Ramírez T. ${ }^{1,2}$, Marcelo Devaud J. ${ }^{1,2}$ y Alejandro López C. ${ }^{2}$

Paciente de sexo femenino de 51 años consulta por disnea, dolor torácico y tos. Estudio con tomografía computada evidencia gran masa de aspecto neoplásico que ocupa la totalidad del hemitórax izquierdo, con desviación del mediastino y desplazamiento caudal del diafragma. El tumor es de densidad heterogénea con zonas calcificadas hacia apical. El pulmón izquierdo está completamente atelectásico, hay desviación de la vía aérea, existe una dextrocardia compensatoria, el tumor respeta la pared torácica y no hay evidencia de diseminación
(Figura 1). Por lo alterado de la anatomía y alto riesgo de sangrado operatorio, en evaluación junto a cirugía vascular se decide instalación de endoprótesis de aorta torácica más angioembolización de arterias torácica interna y torácica lateral (Figura 2). En un segundo tiempo quirúrgico se realiza resección tumoral por doble toracotomía, más resección de sexta costilla para ampliar campo quirúrgico. Se reseca tumor de $3.620 \mathrm{~g}$ dependiente de la pleura visceral (Figura 3). Evolución favorable, con alta al séptimo día posoperatorio. Biopsia: tumor fibroso
'Servicio de Cirugía, Hospital Base Osorno. Osorno, Chile. 2Campo Clínico Osorno Facultad de Medicina, Universidad Austral de Chile. Osorno, Chile.

Recibido 2020-10-29 y aceptado 2020-01-13

Correspondencia a: Dr. Jorge Lavanderos F. jlavanderosfernandez@yahoo. com

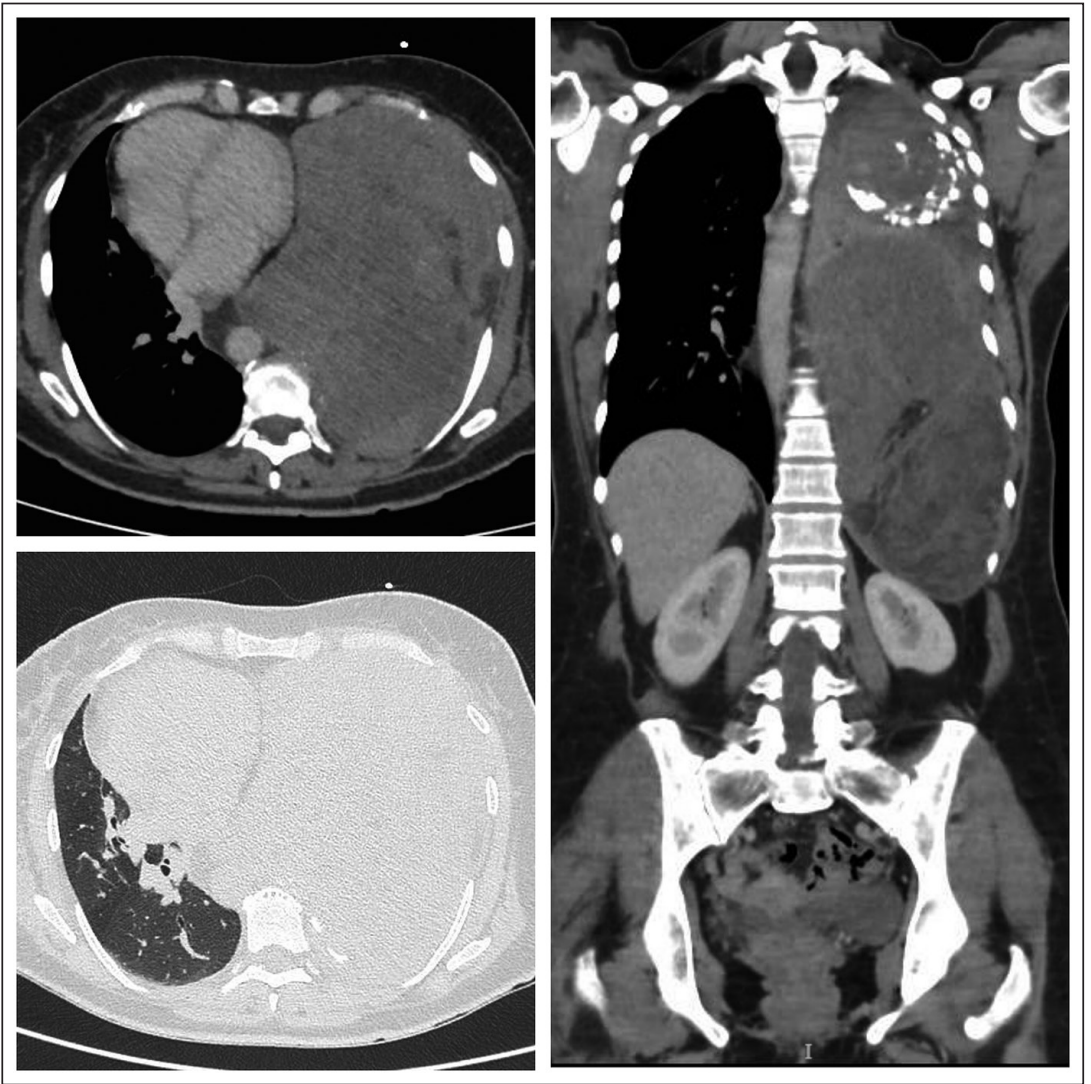

Figura 1. TC visión axial (derecha) y coronal (izquierda) de tumor fibroso solitario gigante. 

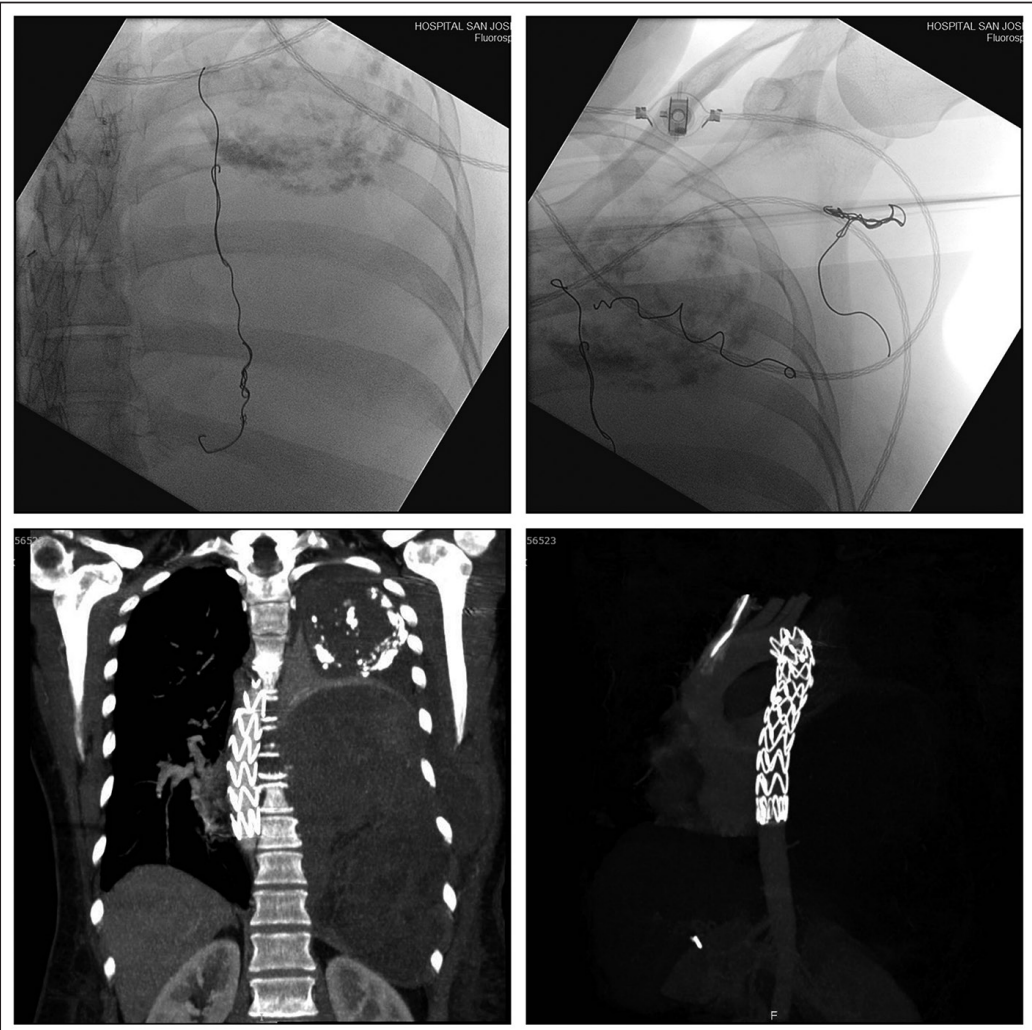

Figura 2. Imagen de sustracción de endoprótesis de aorta torácica e instalación de coils en arterias torácicas interna y lateral (superior). AngioTC con endoprótesis de aorta torácica, visión coronal y reconstrucción 3D (inferior).

solitario de la pleura. En seguimiento en policlínico, paciente asintomática (Figura 4).

El tumor fibroso solitario es un tumor de origen mesenquimal de lento crecimiento; su tratamiento de elección es la resección quirúrgica ${ }^{1,2}$. El uso de endoprótesis de aorta torácica se fundamenta en la obstrucción aguda de las arterias intercostales que permite disminuir el aporte sanguíneo al tumor y de esta manera disminuir el sangrado operatorio ${ }^{3}$. El uso de embolización arterial para disminuir los sangrados operatorios es anecdótico en cirugía torácica,

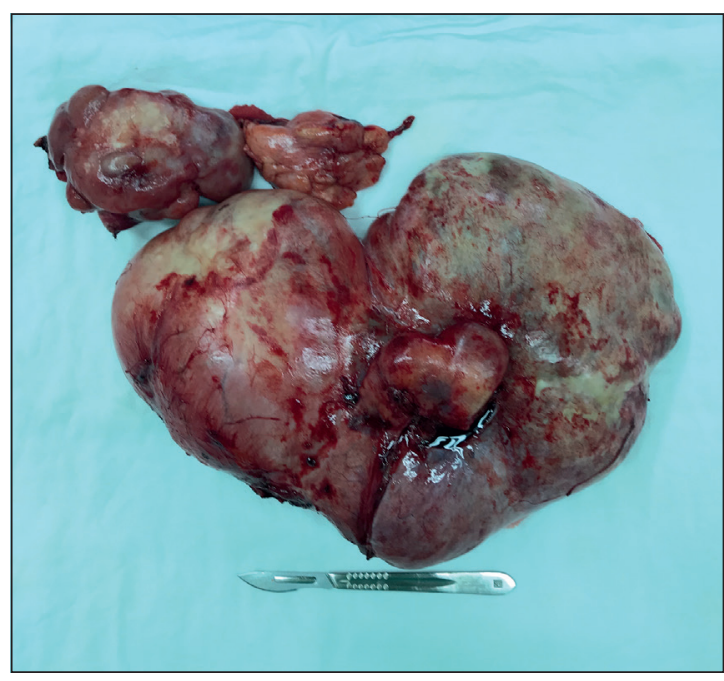

Figura 3. Pieza quirúrgica.

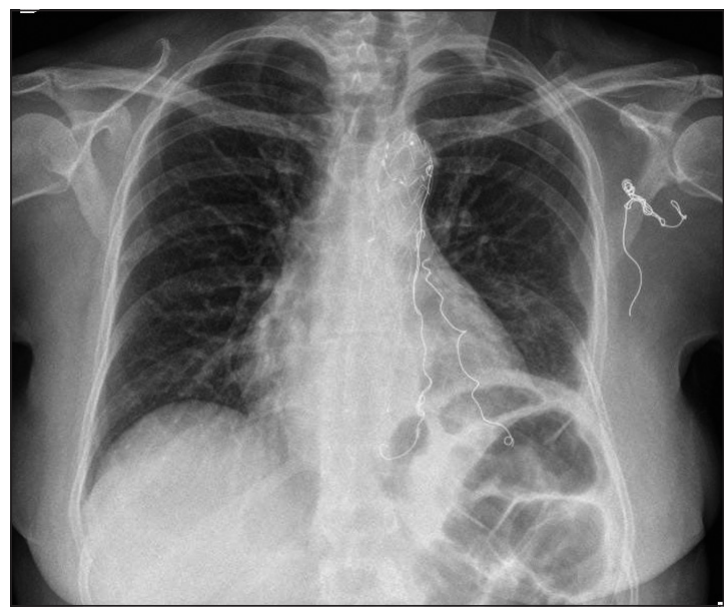

Figura 4. Radiografía de tórax, control ambulatorio.

hay mayor experiencia en cirugía ginecológica ${ }^{4}$. La experiencia a nivel torácico corresponde a la embolización de las arterias bronquiales en el manejo de la hemoptisis ${ }^{5}$.

\section{Bibliografía}

1. Chu X, Zhang L, Xue Z, Ren Z, Sun Y, Wang M, et al. Solitary fibrous tumor of the pleura: An analysis of forty patients. Journal Thorac Dis. 2012;4:146-54.

2. Boddaert G, Guiraudet P, Grand B, Venissac N, Le Pimpec-Barthes F,
Mouroux J, et al. Solitary Fibrous Tumors of the Pleura: A Poorly Defined Malignancy Profile. Ann Thorac Surg. 2015;99:1025-31.

3. Valji K. Thoracic Aorta. Practise the interventional radiology 2012;6: 127-55

4. Dariushnia S, Nikolic B, Stokes L, Spies J. Quality Improvement Guidelines for Uterine Artery Embolization for Symptomatic Leiomyomata. Journal of Vascular and Interventional Radiology 2014;25:1737-47.

5. Cordovilla R, Bollo de Miguel E, Núñez A, Cosano F, Herráez I, Jiménez R.

Diagnosis and treatment of hemoptysis. Arch Bronconeumología 2016;52:368-77. 